慶應義塾大学学術情報リポジトリ

Keio Associated Repository of Academic resouces

\begin{tabular}{|c|l|}
\hline Title & A TEACHING MODEL OF THE "KEYNESIAN" SYSTEM \\
\hline Sub Title & \\
\hline Author & HARCOURT, G. C. \\
\hline Publisher & Keio Economic Society, Keio University \\
\hline Publication year & 1969 \\
\hline Jtitle & Keio economic studies Vol.6, No.2 (1969. ) ,p.23-46 \\
\hline JaLC DOI & \\
\hline Abstract & \\
\hline Notes & \\
\hline Genre & Journal Article \\
\hline URL & $\begin{array}{l}\text { https://koara.lib.keio.ac.jp/xoonips/modules/xoonips/detail.php?koara_id=AA00260492-1969000 } \\
\text { 2-0023 }\end{array}$ \\
\hline
\end{tabular}

慶應義塾大学学術情報リポジトリ(KOARA)に掲載されているコンテンッの著作権は、それぞれの著作者、学会または出版社/発行者に帰属し、その権利は著作権法によって 保護されています。引用にあたっては、著作権法を遵守してご利用ください。

The copyrights of content available on the KeiO Associated Repository of Academic resources (KOARA) belong to the respective authors, academic societies, or publishers/issuers, and these rights are protected by the Japanese Copyright Act. When quoting the content, please follow the Japanese copyright act. 


\title{
A TEACHING MODEL OF THE “KEYNESIAN" SYSTEM*
}

\author{
BY G. C. HaRcourt
}

\section{INTRODUCTION}

1. The purpose of these notes is to outline for teaching purposes a version of the "Keynesian" model of income-determination in the short period. A feature of the model is that it can handle with very simple algebra the interrelations between the money, goods and labour markets, oligopolistic pricing behaviour and the different consumption behaviour of profit-receivers and wageearners. The two key expressions are those for the short-run, equilibrium levels of real output and the rate of interest. The model is, if you like, "Ackley in Algebra"(1) (although the treatment of the price level and the production function differs from Ackley's). The preference for the use of algebra rather than geometry arises from the view that the "quadrant" approach can mislead students, who may settle for mechanical drill; it may confuse them about the applicability of their results and geometry does not always bring out clearly the limitations of the methodology used. These dangers are more easily avoided, it is believed, when algebra is used.

2. The analysis is essentially comparative statics:-first, the derivation of the equilibrium values of real income and the rate of interest from the underlying behavioural relationships and equilibrium conditions, and secondly, comparisons of differences, that is, of new equilibrium values with either the old (preceding) ones or with what they would have been in the "otherwise" situation, when the values of the variables and/or the form of the relationships are changed. Nothing is said, formally about the process of getting from one equilibrium position to another, or whether the economy will actually do so, and any statement about changes as opposed to differences requires an act of faith (which is common to all believers but is not always made explicit). That comparative statics results are so applied to process situations is not stressed enough in the text books.

* I am most grateful to Denzo Kamiya for suggesting a considerable improvement to the form of the $M_{2}$ function and to Tatsuro Ichiishi for working out the implications of this for the analysis. The paper is dedicated to the 1967 Economics III A Class of the University of Adelaide who acted as the unwilling guinea pigs on whom the ideas of the paper were tried out, and who, though they protested vigorously via wall posters, nevertheless refrained from actual violence to the person of the author (except on the football field). "Keynesian" is, of necessity, in quotes in the title following the publication of Axel Leijonhufvud's On Keynesian Economics and the Economics of Keynes (London: Oxford University Press, 1968.)

(1) - Gardner Ackley, Macroeconomic Theory, (New York: Macmillan, 1961). 
3. The analysis is short period: the aim is to find the equilibrium values of output and the rate of interest in a period of calendar time of, say, three to six months. The capital stock is given and constant, and prices and money wages are assumed to be decided and held for this period of time (see below, paras 3.1 and 3.2).

4. The argument is presented in a number of stages. First, only the goods and money markets are considered. The money market contains two assetsthe stock of money (exogenously determined) and bonds. Using a one-commodity, closed two-sector model, and with all relationships assumed to be linear functions, the basic expressions for the short-run, equilibrium levels of real output and the rate of interest are obtained. Secondly, a three-asset money market is included to allow a discussion of the Radcliffe Committee, Gurley and Shaw model. ${ }^{(2)}$ The analysis is then extended by introducing the labour market and the short-run aggregate production function, price-making and the price level, and different consumption behaviour by wage-earners and profit-receivers. This allows a discussion of the impacts of different price levels and different distributions of real income on the equilibrium values.

\section{THE SIMPLEST CASE: GOODS AND MONEY MARKETS}

The equilibrium conditions

1.1. The equilibrium condition in the goods market is that plans and actuality coincide, i.e., that aggregate planned (and actual) spending match actual output (or, ex ante and ex post investment equal ex ante and ex post saving). The equilibrium condition in the money market is that the demand for money equal the supply of money, i.e., that the rate of interest settles at a level where people are content to hold the exogenously given stock of money.

The basic relationships

1.2. (i) The goods market

(a) The consumption function

This is the usual relationship in real terms,

$$
\begin{gathered}
C=\bar{A}+c Y_{p}=\bar{A}+c Y, \\
\left(\text { as } Y=Y_{p}\right)
\end{gathered}
$$

where

$$
\begin{aligned}
C & =\text { consumption expenditure; } \\
\bar{A} & =\text { autonomous item in the consumption function; } \\
c & =\text { aggregate mpc.; }
\end{aligned}
$$

(2) Report of the Committee on the Working of the Monetary System (London: 1959); J. G. Gurley and E. G. Shaw, Money in a Theory of Finance, (Washington D.C.: The Brookings Institution, 1960). 
and

$Y=$ real income (and $Y_{p}=$ real personal disposable income).

1.3. (b) The investment function

Planned investment expenditure in real terms, following Keynes and taking as given the state of short-term and long-term expectations, is regarded as a simple, decreasing function of the rate of interest.

i.e.,

$$
I=\bar{I}-a r,
$$

where

$I=$ planned investment expenditure per period;

$a=$ the slope of the line, i.e., the absolute responsiveness of planned investment expenditure to changes in the rate of interest;

$r=$ rate of interest;

and

$\bar{I}=$ the level of investment expenditure when $r=0$, which could, perhaps, be regarded as autonomous investment expenditure in a very special sense.

The two functions are shown in Figs. $1 \mathrm{a}$ and $1 \mathrm{~b}$.

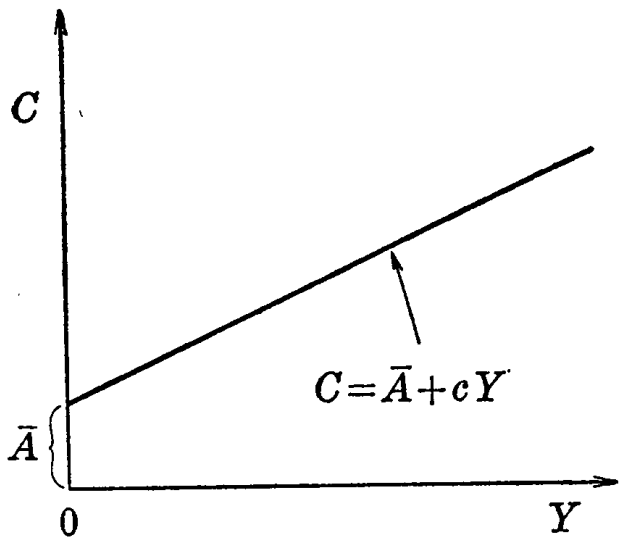

Fig. 1a

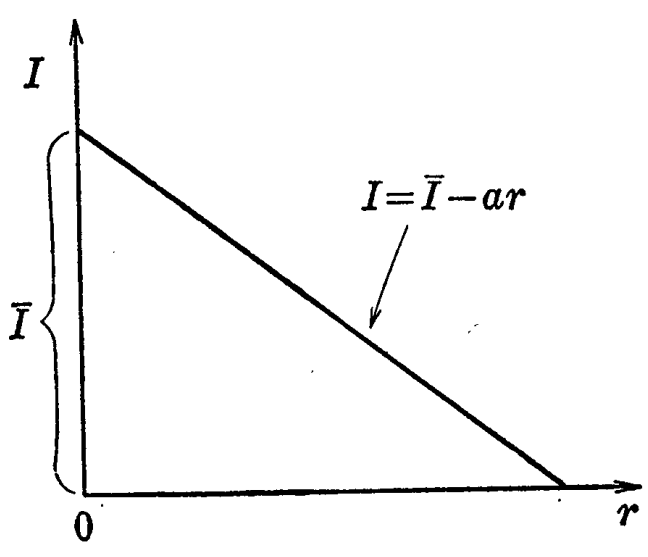

Fig. 1b

1.4. Because $I$ is related to $r$, the aggregate demand schedule-the sum of planned consumption and investment spending-and the equilibrium level of output cannot be determined until the rate of interest is known. And, as will be shown below, the rate of interest cannot be determined until the level of output is known. The two key equilibrium values therefore have to be determined simultaneously, i.e., they are those values of the level of output and the rate of interest which, together, are consistent with (satisfy) the equilibrium conditions in both markets. 


\section{5. (ii) The money market}

(a) The demand for active balances

This relationship is the demand for money to satisfy the transactions motive. It is regarded as a simple proportional function of the level of activity (measured in real terms in the present simple case but, in general, in money terms, see below, para 3.9).

$$
M_{1}=l Y,
$$

where

$M_{1}=$ the demand for active balances;

$l=$ a constant reflecting the public's present spending habits and other transaction motives.

(b) The demand for idle balances

1.6. This is the Keynesian liquidity preference function: the demand for money to satisfy the speculative motive. It is a function of the rate of interest and reflects peoples' uncertainty now about the future level of the rate of interest. It has two features; first, the function is downward sloping and interest-elastic. Secondly, it is perfectly elastic at a minimum positive rate of interest-the "liquidity trap" level.

1.7. The liquidity preference function may be drawn as a curve with a vertical stretch at the "liquidity trap" level of the rate of interest, $r^{*}$ (see Fig. 2). ${ }^{(3)}$ This curve may be approximated by two straight lines (the dotted lines in Fig. 2). They are, respectively, a vertical line at $r=r^{*}$, of which only the section above $A$ has economic meaning, and the line $B C$, of which only the section $A C$ has economic meaning. The equation of the line $B C$ is:

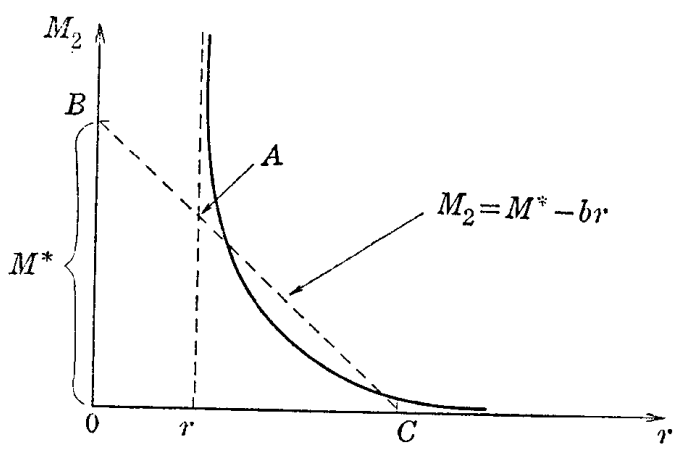

Fig. 2

(3) Usually the rate of interest is measured on the vertical axis and the demand for money is measured on the horizontal axis; this follows the Marshallian tradition of putting dependent and independent variables on their respectively "wrong" axes. By reversing this procedure in order to follow the usual mathematical convention I am trying to do for the liquidity preference function what Professor Knight failed to do for supply and demand curves. 


$$
M_{2}=M^{*}-b r,
$$

where

$M_{2}=$ the demand for idle balances;

$b=$ the slope of the line, i.e., the absolute responsiveness of the demand for idle balances to changes in the rate of interest;

and

$M^{*}=$ vertical intercept on the $M_{2}$ axis, which has no economic meaning.

(c) The supply of money

$$
M=\bar{M},
$$

where

$\bar{M}=$ the exogenously given stock of money.

The Equilibrium values

1.8. The equilibrium values of $Y$ and $r$ may be obtained from the two equilibrium conditions.

The goods market condition

i.e.,

$$
Y=E(=C(Y)+I(r))
$$

$$
\begin{aligned}
Y & =\bar{A}+c Y+\bar{I}-a r \\
& =\frac{\bar{A}+\bar{I}-a r}{1-c},
\end{aligned}
$$

where

$$
E=\text { aggregate demand } .
$$

(Expression (1.6), when written as: $r=\frac{\bar{A}+\bar{I}}{a}-\left(\frac{1-c}{a}\right) Y$, is the Hicks-

Hansen IS schedule.)

The money market condition

i.e.,

$$
\bar{M}=M_{1}(Y)+M_{2}(r)
$$

$$
\bar{M}=l Y+M^{*}-b r .
$$

1.9. Expression (1.7) may be solved for $r$ to give:-

$$
r=\frac{l Y+M^{*}-\bar{M}}{b} \quad\left(=\frac{M^{*}-\bar{M}}{b}+\frac{l}{b} Y\right)
$$

(This is the Hicks-Hansen $L M$ schedule.)

Substituting (1.8) in (1.6), the expression for the equilibrium level of real income is obtained, viz., 


$$
Y=\frac{\bar{A}+\bar{I}-\frac{a}{b}\left(M^{*}-\bar{M}\right)}{1-c+\frac{a}{b} l} .
$$

Finally, by substituting (1.9) in (1.8), and rearranging terms, the corresponding expression for the equilibrium value of the rate of interest is obtained:

$$
r=\frac{l(\bar{A}+\bar{I})+\left(M^{*}-\bar{M}\right)(1-c)}{b\left(1-c+\frac{a}{b} l\right)}
$$

(provided $r>r^{*}$ ).

(The values implied by (1.9) and (1.10) correspond to the values of $Y$ and $r$ associated with the intersections of the $I S(1.6)$ and $L M(1.8)$ schedules.) $)^{(4)}$

1.10. It should be noticed that the value of $r$, so obtained, must be greater than $r^{*}$. If it is not, the "liquidity trap" level of the rate of interest prevails, idle balances will absorb whatever cash remains after the needs of active balances have been met, i.e., idle balances are purely residual, and the level of activity will be determined by the consumption function and the level of investment expenditure associated with the "liquidity trap" level of the rate of interest. The money market therefore has no impact (other than this) on the goods market, and the equilibrium level of real income is obtained from the goods market equilibrium condition, $Y=E$, alone.

Thus

$$
Y=E=\bar{A}+c Y+\bar{I}-a r^{*}
$$

i.e.,

$$
Y=\frac{\bar{A}+\bar{I}-a r^{*}}{1-c}
$$

(4)

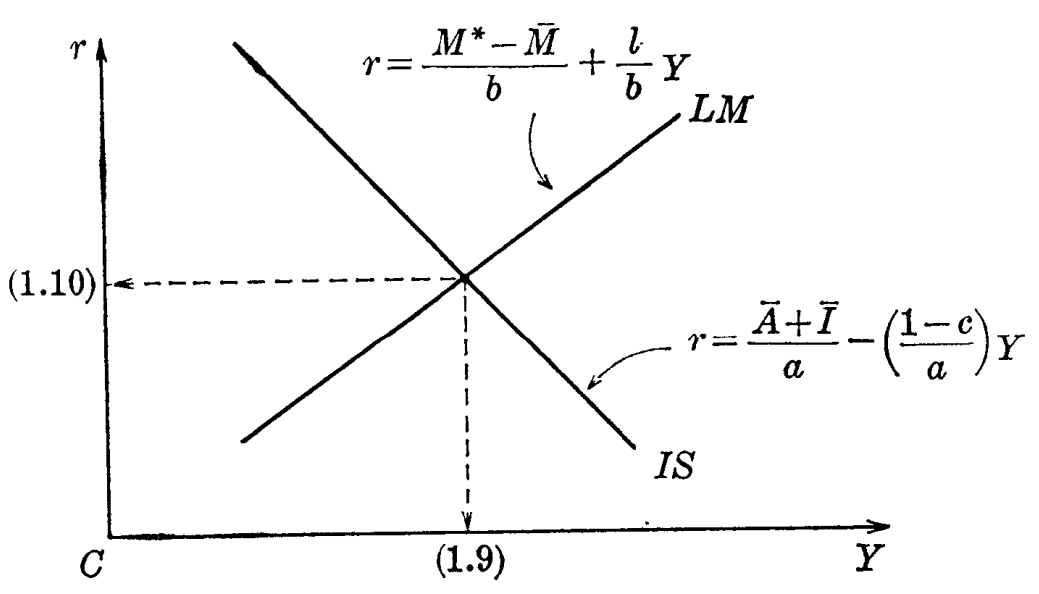

(5) It is assumed that $\bar{M} \geq l Y=l\left\{\frac{\bar{A}+\bar{I}-a r^{*}}{1-c}\right\}$. 
That $r=r^{*}$ is, of course, a very important possibility which should not be lost sight of. For the remainder of these notes, though, it will be assumed that the value of $r$ in equation (1.10) exceeds $r^{*}$ and that the value of $Y$ in equation (1.9) is greater than $\frac{b r^{*}+\bar{M}-M^{*}}{l}$, the value of $Y$ at which $r=r^{*}$ in (1.8), but is less than the full employment level of real output. ${ }^{(6)}$

1.11. Equation (1.9) contains elements which are familiar from the simple goods market model of income-determination, namely, the autonomous items of expenditure, $\bar{A}$ and $\bar{I}$, and $\frac{1}{1-c}$, the expression for the simple multiplier. That (1.9) reduces to $Y=\frac{\bar{A}+\bar{I}}{1-c}$ may be seen by supposing that the quantity of money is such that the equilibrium level of income is $\frac{\bar{A}+\bar{I}}{1-c}$ and that the equilibrium rate of interest, if it could be established, is zero. The required value of the stock of money may be found by solving for $\bar{M}$ in

i.e.,

$$
\frac{\bar{A}+\bar{I}-\frac{a}{b}\left(M^{*}-\bar{M}\right)}{1-c+\frac{a}{b} l}=\frac{\bar{A}+\bar{I}}{1-c}
$$

$$
\bar{M}=l\left(\frac{\bar{A}+\bar{I}}{1-c}\right)+M^{*}
$$

With this value of the stock of money, $Y=\frac{\bar{A}+\bar{I}}{1-c}$ and only a zero value of $r$ is consistent with money market equilibrium. Thus

i.e.,

$$
\bar{M}=M_{1}+M_{2} ;
$$

$$
l\left(\frac{A+\bar{I}}{1-c}\right)+M^{*}=l\left(\frac{\bar{A}+\bar{I}}{1-c}\right)+M^{*}-b r,
$$

which is only true when $r=0$.

1.12. So much for special casery. In the general case, the multiplier, which is now $\left(\frac{1}{1-c+(a / b) l}\right)$, is seen to be reduced in value, relative to the simple case of $\frac{1}{1-c}$, by elements which determine the absorption into active

(6) At $Y \gtrless \frac{b r^{*}+\bar{M}-M^{*}}{l}\left(=Y^{*}\right)$, the amount of money available for idle balances is $\$ M^{*}-b r^{*}$, the demand for money for idle balances at the intersection of $(1.4 \mathrm{~b})$ with the vertical line at $r=r^{*}$. Thus when $Y>Y^{*}, r$ must be greater than $r^{*}$ so that cash is released. from idle balances to finance the higher level of active balances. 
balances as activity rises. These elements are, respectively, the (absolute) responsiveness of planned investment spending to changes in $r(i . e ., a)$, the (absolute) responsiveness of the demand for idle balances to changes in $r(i . e ., b)$, and the public's habits with regard to active balances (i.e., $l$ ). If $a$ is small, so that planned investment expenditure is little affected by a given change in $r$, if $b$ is large, so that the demand for idle balances is greatly affected by a given change in $r$, and if the public economises greatly in the use of active balances, so that $l$ is small, the monetary factors have little impact on the flow of induced spending and the value of the multiplier will be close to the simple value.

1.13. The multiplicand, $\bar{A}+\bar{I}-\frac{a}{b}\left(M^{*}-\bar{M}\right)$, also has monetary factors in it. $M^{*}$ may be regarded as the shift factor of the liquidity preference function-the greater is its value, the greater will be the cash demanded for idle balances at any given rate of interest and, cet par, the lower will be the level of economic activity associated with any given money stock. Given the value of $M^{*}$, the magnitude of its impact depends on the relative values of $a$ and $b$. Similarly, the greater is the quantity of money, the higher will be the level of planned investment spending and therefore the greater will be the level of economic activity. The impact of a given quantity of money on the level of economic activity through the multiplicand also depends on the value of $a / b$.

1.14. The value of the equilibrium rate of interest will be greater, the larger are the values of $\bar{A}$, and $\bar{I}$ and $M^{*}$, and smaller, the larger is the value of $\bar{M}$. The impact of $M^{*}$ perhaps needs explaining (the other results are clear intuitively). The larger is the value of $M^{*}$, the larger is the demand for idle balances at any given rate of interest. Therefore it is to be expected that the higher is the value of $M^{*}$, the higher will be the equilibrium value of $r$ and the lower will be the equilibrium value of $Y$.

1.15. The impact of different values of $l, a$ and $b$ on the equilibrium value of $r$ is ambiguous (this is not always true of their impact on the equilibrium value of $Y$ ). The different values give rise to conflicting effects on the demand for money and the level of activity. For example, a fall in the value of $l$ means that, per unit of real output, active balances are economised on and so $r$ would tend to fall. On the other hand, a tendency for $r$ to fall will stimulate a rise in activity which will offset the initial fall in $r$. Which effect predominates depends on the values of other coefficients and autonomous items. ${ }^{(7)}$

(7) If (1.10) is partially differentiated with respect to $l$, whether

$$
\frac{\delta r}{\delta l} \gtrless 0 \quad \text { depends upon whether }(\bar{A}+\bar{I}) \gtrless \frac{a}{b}\left(M^{*}-\bar{M}\right) .
$$

It is not obvious which of these conditions is most likely to be met. 
1.16. This section is concluded by setting out the impact of unit increases in $\bar{I}, \bar{A}, M^{*}$ and $\bar{M}$ respectively, on the equilibrium levels of real income and the rate of interest (see Table 1.1). The signs of the resulting changes are also shown.

TABLE 1.1

\begin{tabular}{c|c|c|c|c}
\hline Unit change in & $\bar{I}$ & $\bar{A}$ & $M^{*}$ & $\bar{M}$ \\
\hline $\begin{array}{c}\text { Resulting change in } \\
Y\end{array}$ & $\frac{1}{1-c+\frac{a}{b} l}$ & As for $\bar{I}$ & $-\frac{\frac{a}{b}}{1-c+\frac{a}{b} l}$ & $\frac{\frac{a}{b}}{1-c+\frac{a}{b} l}$ \\
$r$ & $\frac{l}{b\left(1-c+\frac{a}{b} l\right)}$ & As for $\bar{I}$ & $\frac{1-c}{b\left(1-c+\frac{a}{b} l\right)}$ & $-\frac{1-c}{b\left(1-c+\frac{a}{b} l\right)}$ \\
\hline
\end{tabular}

2. THE RADCLIFFE COMMITTEE, GURLEY AND SHAW MODEL

2.1. So far a strictly "Keynesian" analysis has been presented. In this section some post-"Keynesian" developments associated with the Radcliffe Committee and the works of Gurley and Shaw are introduced. ${ }^{(8)}$ The essential point of these developments is that businessmen and consumers demand "liquidity" rather than money alone in order to satisfy the transactions and speculative motives. The money market must therefore be regarded as containing at least three assets-money, near-money and bonds, where near-money is short-term assets such as treasury bills and other assets which are traded on the short-term money market.

2.2. As a result of the existence of near-money, shifts in the functions of the demands for active and idle balances become important determinants of the levels of activity and the rate of interest in the short run. If planned spending rises, it is argued that economies will be made in the use of active balances, so that the demand for active balances will not rise proportionately with (money) income. Therefore $l$ cannot be regarded as a constant. Moreover, the liquidity preference schedule may move to the left as well; people may prefer to hold near-money rather than bonds as activity rises because the capital loss is smaller and can be avoided altogether by holding the assets for only a short period of time. ${ }^{(9)}$

(8) An excellent account of the implications of these developments for the "Keynesian" model is to be found in Laurence S. Ritter, "The Role of Money in the Keynesian System", in M. G.Mueller (ed.), Readings in Macroeconomics. (New York: Holt, Rinehart and Winston, 1966). The analysis of this section is an algebraic presentation of Ritter's arguments.

(9) See Lawrence S. Ritter, "The Role of Money in the Keynesian System", p. 167. 
2.3. These effects are fitted easily into the model presented in Section 1 by making $l$ and $M^{*}$ variables which are functions of the levels of autonomous. planned expenditures, $\bar{A}$ and $\bar{I} . \quad(\bar{A}$ and $\bar{I}$ are the parameters of the consumption and investment functions which determine their respective positions; changes in $\bar{A}$ and $\bar{I}$ cause the functions to shift.) Thus,

$$
l=\bar{l}-j(\bar{A}+\bar{I})
$$

and

$$
M^{*}=\bar{M}^{*}-k(\bar{A}-\bar{l}) .
$$

Writing (2.1) and (2.2) in this form allows the demand for active balances to increase less than proportionately when income rises and produces the leftward. shift in the liquidity preference schedule.

2.4. The expressions for the equilibrium values of $Y$ and $r$ now become:-

$$
Y=\frac{(\bar{A}+\bar{I})-\frac{a}{b}\left(\bar{M}^{*}-k(\bar{A}+\bar{I})-\bar{M}\right)}{1-c+\frac{a}{b}(\bar{l}-j(\bar{A}+\bar{I}))}
$$

and

$$
r=\frac{\{\bar{l}-j(\bar{A}+\bar{I})\}\{\bar{A}+\bar{I}\}+\left\{\bar{M}^{*}-k(\bar{I}+\bar{A})-\bar{M}\right\}(1-c)}{b\left(1-c+\frac{a}{b}(\bar{l}-j(\bar{A}+\bar{I}))\right)}
$$

2.5. It can be seen that (2.3) and (2.4) reduce to (1.9) and (1.10), respectively, if $l$ and $M^{*}$ are constants rather than variables. Now suppose that. values of $\bar{l}, \bar{M}^{*}, j$ and $k$, are chosen such that for given initial values of $\bar{A}$ and $\bar{I}$, the values of $Y$ and $r$ implied by (2.3) and (2.4) are the same as those implied by (1.9) and (1.10) respectively. Then it is clear that a rise in $\bar{A}$ and/or $\bar{I}$ will have a greater impact on the equilibrium value of $Y$ in the Radcliffe Committee, Gurley and Shaw model than in the "pure" "Keynesian" case. It can also be shown that while the value of $r$ in the "Keynesian" case rises. when $\bar{A}$ and/or $\bar{I}$ are increased, it may fall in the Radcliffe Committee, Gurley and Shaw case; and, even if it rises, it certainly will not rise by as much as. in the "Keynesian" case. ${ }^{(10)}$ It is results of this nature which have lead to suspicion of "pure" monetary policy and concentration, instead, on the importance of overall liquidity.

2.6. It should be added that this is as far as this particular form of analysis can go. $\left[M^{*}-k(\bar{A}+\bar{I})\right]$ and $[\bar{l}-j(\bar{A}+\bar{I})]$ are not reversible functions.

(10) To show this, partially differentiate (1.10) and (2.4) with respect to $(\bar{A}+\bar{I})$. For $(1.10)$,

$$
\frac{\delta r}{\delta(\bar{A}+\bar{I})}=\frac{l}{b\left(1-c+\frac{a}{b} l\right)} \text {. }
$$


The economies in the use of active (and idle) balances once learnt, are not forgotten. This model therefore can be used only to make the point that the rise in activity is likely to be greater, following a rise in autonomous expenditure, and the change in the rate of interest is likely to be less, than would be predicted by the simple "Keynesian" model with a two-asset money market.

\section{THE COMPLEX CASE-GOODS, MONEY AND LABOUR MARKETS, THE DISTRIBUTION OF INCOME AND THE PRICE LEVEL}

3.1. In this section the labour market and the price level are considered as well as the goods and money markets; the short-run aggregate production function and the different values of the mpc's of wage-earners and profitreceivers, respectively, are introduced. No (short-run) equilibrium condition is assumed in the labour market, i.e., it is assumed that equilibrium in both the money and the goods markets in the short run is consistent with the existence of involuntary unemployment. It is also assumed that the money-wage rate is given for the period of the analysis, i.e., that money wage bargains are remade period by period (and are influenced by factors such as the current level of unemployment, and changes in prices and (national) productivity) but are held for the period concerned.

3.2. Similarly, prices are assumed to be constant for the period concerned but to change from period to period due to changes in capacity, labour productivity, expected sales and the money-wage rate. A very simple form of oligopolistic pricing is assumed, namely, that firms mark up their average wage

For (2.4)

(2.2a)

$$
\frac{\delta r}{\delta(\bar{A}+\bar{I})}=\frac{+\left(\frac{a}{b} j\right)\left\{(\bar{l}-j(\bar{A}+\bar{I}))(\bar{A}+\bar{I})+(1-c)\left(\bar{M}^{*}-k(\bar{A}+\bar{I})-\bar{M}\right)\right\}}{b\left\{1-c+\frac{a}{b}(\bar{l}-j(\bar{A}+\bar{I}))\right\}^{2}}
$$

(2.2a) may be written as:-

$$
\begin{aligned}
& \frac{\bar{l}-2 j(\bar{A}+\bar{I})-(1-c) k}{\left.b\left(1-c+\frac{a}{b} \bar{l}-j(\bar{A}+\bar{I})\right)\right)} \\
& +\frac{\left(\frac{a}{b} j\right)\left[\{\bar{l}-j(\bar{A}+\bar{I})\}\{\bar{A}+\bar{I}\}+(1-c)\left\{\bar{M}^{*}-k(\bar{A}+\bar{I})-\bar{M}\right\}\right]}{b\left\{1-c+\frac{a}{b}(\bar{l}-j(\bar{A}+\bar{I}))\right\}^{2}}
\end{aligned}
$$

The first part of the expression is $<(2.1 \mathrm{a})$ and, for some reasonable values of $k$, et al., may be $<0$; the second part of the expression, while almost certainly $>0$, is small in relation to the first part. 
costs by a percentage mark up, ${ }^{(11)}$ the value of which is determined by existing capacity and expected sales. It could be argued that the greater is the existing level of capacity, the smaller will be the mark-up; and the greater is the level of expected sales, the higher will be the mark-up. Constant rather than diminishing returns to labour are assumed in the short run. These simple assumptions are more in accord with empirical findings concerning pricing and production behaviour in manufacturing industry ${ }^{(12)}$ than the usual ones of flexible prices, perfect competition in the goods market, and diminishing marginal productivity of labour in the short run. All relevant quantities, unless the contrary is stated, are measured in terms of base period prices (indicated by the subscript $b$ ).

The labour market and money wages

3.3. The demand for labour may be written as:

$$
N=\alpha Y,
$$

where

$N=$ employment per period;

$\alpha=$ labour requirement per unit of output (the inverse of labour productivity).

and

$$
Y=\text { real output, }
$$

i.e., the demand for labour is simply a derived demand from the goods market determined by expected sales and the short-run aggregate production function.

The money wage equation is:-

$$
w=\bar{w},
$$

where

$w=$ money wage

and

$\bar{w}=$ current value.

The price level

3.4. The current price of a unit of aggregate real output $\left(P_{t}\right)$ is:-

$$
\begin{aligned}
P_{t} & =\frac{\bar{w} N}{Y}(1+\bar{v}) \\
& =\alpha \bar{w}(1+\bar{v}),
\end{aligned}
$$

(11) Strictly speaking, it is their average direct costs which firms mark-up. But, for the economy as a whole, raw material costs cancel out and it is as if overall average wage costs were marked-up.

(12) See, for example, R. R. Neild, Pricing and Employment in The Trade Cycle. (London: Cambridge University Press, 1964.) 
where

$\bar{v}=$ the percentage mark-up.

The price in base period $\left(P_{b}\right)$ is:-

$$
P_{b}=\alpha_{b} \bar{w}_{b}\left(1+\bar{v}_{b}\right) \equiv 1
$$

as $P_{b}$ is the numeraire. $\quad \alpha_{b}$ is likely to be greater and $\bar{w}_{b}$ is likely to be less than its current counterpart, but $\bar{v}_{b}$ may be $\gtrless \bar{v}_{t}$.)

The goods market

(a) The consumption function

3.5. To obtain an expression for the consumption function, it is necessary, first, to look at the national accounts of any period. GNI in terms of current prices is:-

$$
Y_{m} \equiv W+P
$$

where

and

$$
\begin{aligned}
W & =\text { total wages } \\
P & =\text { total profits }
\end{aligned}
$$

Now

$$
Y_{m} \equiv \bar{w} N+\bar{v} \bar{w} N \equiv \bar{w} \alpha Y+\bar{v} \bar{w} \alpha Y \equiv \alpha \bar{w} Y(1+\bar{v}) .
$$

It follows that output in base period prices, i.e., in real terms, is:-

$$
Y \equiv Y_{m} \frac{P_{b}}{P_{t}} \equiv \alpha \bar{w} Y(1+\bar{v}) \frac{P_{b}}{P_{t}}
$$

3.6. It can be seen from (3.5) and (3.6) that the higher is the money-wage rate, the greater is the money value of wages and profits associated with a given level of real output, but that their real values are unchanged because money wages, profits and prices all rise by the same proportion; i.e., if $\bar{w}_{2}>\bar{w}_{1}, \alpha \bar{w}_{2} Y(1+\bar{v})>\alpha \bar{w}_{1} Y(1+\bar{v})\left(\right.$ by $\left.\left\{\frac{\bar{w}_{2}}{\bar{w}_{1}}-1\right\}\right)$, but $\alpha \bar{w}_{2} Y(1+\bar{v}) \frac{P_{b}}{P_{t_{2}}}=$ $\alpha \bar{w}_{1} Y(1+\bar{v}) \frac{P_{b}}{P_{t_{1}}}$. On the other hand, the higher is the value of $\bar{v}$, the higher is the value of total money profits, total money wages remain unchanged, but total real wages are less (and total real profits are correspondingly greater). (The rise in money profits is $\left(\frac{\bar{v}_{2}}{\bar{v}_{1}}-1\right)$ and the rise in prices is $\left(\frac{1+\bar{v}_{2}}{1+\bar{v}_{1}}-1\right)$, which is $\left\langle\left(\frac{\bar{v}_{2}}{\bar{v}_{1}}-1\right)\right.$.) That is to say, there is a shift in the distribution of any given level of real income to profit-receivers.

3.7. The consumption function in terms of current prices may be written as:- 


$$
\begin{aligned}
C_{m} & =\bar{A}_{w, p} \frac{P_{t}}{P_{b}}+c_{w} \alpha \bar{w} Y+c_{p} \bar{v} \alpha \bar{w} Y \\
& =\bar{A}_{w, p} \frac{P_{t}}{P_{b}}+\left(c_{w}+\bar{v} c_{p}\right) \alpha \bar{w} Y,
\end{aligned}
$$

where

$\bar{A}_{w, p}=$ autonomous spending on consumption goods (assumed to be fixed in real terms) by wage-earners and profit-receivers combined,

$c_{w}=$ mpc of wage-earners;

$c_{p}=\mathrm{mpc}$ of profit-receivers;

and

$c_{p}<c_{w}$.

In real terms, i.e., (3.5) is deflated by $\frac{P_{b}}{P_{t}}$,

$$
C=\bar{A}_{w, p}+\left(c_{w}+\bar{v} c_{p}\right) \alpha \bar{w} \frac{P_{b}}{P_{t}} Y .
$$

It should be noted that the higher is the value of $P_{t}$, the greater is the share of real profits in any given level of real income; therefore because $c_{p}<c_{w}$, the lower is the level of planned consumption spending in real terms associated. with this level of real income. ${ }^{(13)}$

(b) The investment function

3.8. This is written as before as, for simplicity, planned investment demands are assumed not to be affected by the price level.

$$
I=\bar{I}-\operatorname{ar} .
$$

\section{The money market}

(a) Demand for active balances

3.9. For obvious reasons, money held in active balances will be related to the current money value of any given level of real output. The $M_{1}$ function. is therefore written:-

$$
M_{1}=l \frac{P_{t}}{P_{b}} Y
$$

((3.10) should be compared with (1.3) above.)

(13) From (3.3) and (3.8) we obtain:

$$
\begin{gathered}
C=\bar{A}_{w, p}+\frac{c_{w}+\bar{v} c_{p}}{1+\bar{v}} P_{b} Y \\
\frac{c_{w}+\bar{v} c_{p}}{1+\bar{v}} \equiv \frac{1}{1+\bar{v}} c_{w}+\frac{\bar{v}}{1+\bar{v}} c_{p},
\end{gathered}
$$

where the "weights," $\frac{1}{1+\bar{v}}$ and $\frac{\bar{v}}{1+\bar{v}}$, are the respective shares of wages and profits in a unit. of output, and $\frac{c_{w}+\bar{v} c_{p}}{1+\bar{v}} P_{b}$ is the overall mpc. It is obvious that, when $\bar{v}$ rises, the first. "weight" declines and the second rises; thus, because $c_{p}<c_{w}$, the overall mpc declines. 
(b) Demand for idle balances

3.10. Keynes probably would have argued that the demand for idle balances was unaffected by the price level, i.e., that people demand, at any given rate of interest, a certain amount of money for speculative purposes which is not, however, fixed in real terms. That is to say, a "money illusion" is present. If Keynes's view is adopted, the $M_{2}$ function may be written as before (i.e., as $M_{2}=M^{*}-b r$, for $\left.r>r^{*}(1.4)\right)$.

3.11. However, if it is believed that people do not suffer from "money illusion," i.e., that they demand, at a given rate of interest, a constant amount of money in real terms, this effect may be allowed for easily by writing the $M_{2}$ function (for $r>r^{*}$ ) as:-

$$
M_{2}=\frac{P_{t}}{P_{b}}\left(M^{*}-b r\right) .
$$

The higher is $\boldsymbol{P}_{t}$, the greater is the demand for money to hold in idle balances at any given value of $r$. In what follows, (3.11) is used rather than (1.4); but "money illusion" easily can be introduced by removing $\frac{P_{t}}{P_{b}}$ from all money terms.

(c) Supply of money

3.12. The supply of money equation is written as before (see (1.5) above):-

$$
M=\bar{M} \text {. }
$$

Equilibrium values of $Y$ and $r$

3.13. Proceeding as before by imposing the equilibrium conditions in the money and goods markets, the following expressions may be obtained:-

(1) Equilibrium rate of interest (first step)

$$
r=\frac{l Y+M^{*}-\frac{P_{b}}{P_{t}} \bar{M}}{b}
$$

(2) Equilibrium level of real income

$$
Y=\frac{\bar{A}_{w, p}+\bar{I}-\frac{a}{b}\left(M^{*}-\frac{P_{b}}{P_{t}} \bar{M}\right)}{1-\alpha \bar{w} \frac{P_{b}}{P_{t}}\left(c_{w}+\bar{v} c_{p}\right)+\frac{a}{b} l} .
$$

(3) Equilibrium rate of interest (second step)

$$
r=\frac{l\left(\bar{A}_{w, p}+\bar{I}\right)+\left(M^{*}-\frac{P_{b}}{P_{t}} \bar{M}\right)\left(1-\alpha \bar{w} \frac{P_{b}}{P_{t}}\left(c_{w}+\bar{v} c_{p}\right)\right)}{b\left(1-\alpha \bar{w} \frac{P_{b}}{P_{t}}\left(c_{w}+\bar{v} c_{p}\right)+\frac{a}{b} l\right)} .
$$


3.14. It should be noted immediately that (3.13), (3.14) and (3.15) reduce to (1.8), (1.9) and (1.10) respectively, if $\frac{P_{t}}{P_{b}}=1$ (or if the price level is ignored), $c_{p}=c_{w}=c$, and $\bar{A}_{w, p}=\bar{A}$. Whenever these conditions do not hold, the new expressions allow the impacts of the price level, different mpc's and the distribution of income on the level of activity and the rate of interest to be analysed. (The Radcliffe Committee, Gurley and Shaw modifications could also be easily introduced.)

3.15. With the new expressions it is possible to answer such (limited) questions as what will be the impact of a lower level of the money wage on the equilibrium values of real output and the rate of interest? What will be the impact of a higher mark-up on the two equilibrium values? Notice again that these are not equivalent to asking: will a wage cut or a rise in the markup in fact raise (or lower) the level of economic activity (though the answer to the second rather than the first of these questions is more likely to be approximated to if the results of the equilibrium comparisons are used).

\section{A lower money wage}

3.16. The lower is the level of the money wage, the higher will be the equilibrium level of $Y$ and the lower will be the equilibrium value of $r$. Examining, first, (3.14), it can be seen that the positive term, $\frac{a}{b} \frac{P_{b}}{P_{t}} \bar{M}$, in the numerator will be higher, the lower is the value of $\bar{w}$. This is the only term affected by a change in the value of $\bar{w}$, and it raises the value of $Y$. (At first sight, $\alpha \bar{w} \frac{P_{b}}{P_{t}}\left(c_{w}+\bar{v} c_{p}\right)$ appears to be affected as well; however, any change in $\bar{w}$ is exactly matched by one of the same amount in $P_{t}$, so that the expression as a whole is not affected. This is as it should be, since, with the present assumptions, (see para 3.6) the distribution of income is not affected by a change in the value of $\bar{w}$.)

3.17. Now examine (3.15), and remember that conflicting factors are at work. On the one hand, the lower is the price level, the lower is the demand for money to satisfy the transactions demand per unit of real output and to satisfy the demand for idle balances at a given rate of interest. These two factors imply a lower rate of interest. On the other hand, the higher is the level of activity, the greater is the proportion of a given stock of money which will go into active balances, and, therefore, the higher will be the rate of interest. It appears, though, that the first two factors outweigh the third, for the only term affected, $-\frac{P_{b}}{P_{t}} \bar{M}\left(1-\alpha \bar{w} \frac{P_{b}}{P_{t}}\left(c_{w}+\bar{v} c_{p}\right)\right)$ in the numerator, is greater, the smaller is the value of $\bar{w}$, with the result that the equilibrium rate of interest is less, the smaller is the value of the money wage rate. 
TABLE 3.1.

\begin{tabular}{|c|c|c|c|}
\hline Unit change in & $\bar{I}, \overline{A_{w, p}}$ & $M^{*}$ & $\bar{M}$ \\
\hline $\begin{array}{c}\text { Resulting change in } \\
Y\end{array}$ & 1 & 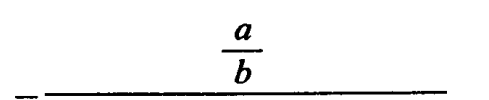 & $\frac{a}{b} \frac{P_{b}}{P_{t}}$ \\
\hline$Y$ & $\begin{array}{c}\overline{1-\alpha \bar{w} \frac{P_{b}}{P_{t}}\left(c_{w}+\bar{v} c_{p}\right)+\frac{a}{b} l} \\
l\end{array}$ & $\begin{array}{c}1-\alpha \bar{w} \frac{\boldsymbol{P}_{b}}{\boldsymbol{P}_{t}}\left(c_{w}+\bar{v} c_{p}\right)+\frac{a}{b} l \\
1-\alpha \bar{w} \frac{\boldsymbol{P}_{b}}{\boldsymbol{P}_{t}}\left(c_{w}+\bar{v} c_{p}\right)\end{array}$ & $\begin{array}{l}\overline{1-\alpha \bar{w} \frac{P_{b}}{P_{t}}\left(c_{w}+\bar{v} c_{p}\right)+\frac{a}{b} l} \\
\quad \frac{P_{b}}{P_{t}}\left(1-\alpha \bar{w} \frac{P_{b}}{P_{t}}\left(c_{w}+\bar{v} c_{p}\right)\right) \\
\end{array}$ \\
\hline$r$ & $\overline{b\left(1-\alpha \bar{w} \frac{P_{b}}{P_{t}}\left(c_{w}+\bar{v} c_{p}\right)+\frac{a}{b} l\right)}$ & $\overline{b\left(1-\alpha \bar{w} \frac{P_{b}}{P_{t}}\left(c_{w}+\bar{v} c_{p}\right)+\frac{a}{b} l\right)}$ & 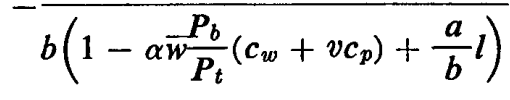 \\
\hline
\end{tabular}

祭 
A higher percentage mark-up

3.18. The higher is the value of the mark-up, the lower is the equilibrium value of real output (beware of monopolists!). The equilibrium value of the rate of interest, however, can be either higher or lower, depending upon the actual values of the conflicting factors at work.

3.19. That the first result is so can be seen by examining (3.14). The value of the positive term, $\frac{a}{b} \frac{P_{b}}{P_{t}} \bar{M}$, in the numerator, is reduced and the value of the negative term $\alpha \underset{w}{P_{t}} \frac{P_{b}}{P_{t}}\left(c_{w}+c_{p}\right)$, in the denominator is also reduced-both of which reduce the value of $Y$.

3.20. The lower equilibrium level of activity would, other things being equal, imply a fall in the equilibrium rate of interest. On the other hand, the higher price level raises the demand for active balances per unit of real output and the demand for idle balances at any given level of the rate of interest. These effects are all reflected in (3.15) but the outcome is, in general, indeterminate.

3.21. For completeness, the impacts of unit increases in $\bar{I}, \bar{A}_{w, p}, M^{*}$ and $\bar{M}$ on the equilibrium values of $Y$ and $r$ are set out in Table 3.1.

4

4.1. The models presented in these notes can be used to answer questions other than those explicitly mentioned. The questions can refer to short period puzzles or period by period problems. In the latter case, the model in Section 3 is especially suited to analysis of the period by period link between money wages, prices, and investment decisions. ${ }^{(14)}$ It is also possible to bring in the rest of the world and government sectors, though, of course, this adds to the complexity of the results. Finally, the present approach makes a convenient link between the simple model of income-determination in the goods market and the capital-stock adjustment models of the trade cycle presented, for example, in R. C. O. Matthews' book on the trade cycle and H. R. Hudson's 1957 article. ${ }^{(15)}$

(14) The forms that these links might take have been discussed in the author's paper, "A Two-Sector Model of the Distribution of Income and the Level of Employment in the Short Run', Economic Record, March 1965.

(15) R. C. O. Matthews, The Trade Cycle (Cambridge: Cambridge University Press, 1959); H. R. Hudson, "A Model of the Trade Cycle" Economic Record, December 1957.

A linear version of Hudson's model is presented in Appendix 2. 


\section{APPENDIX 1}

A1.1. In this appendix the following question is asked: in the simple goods market model, an increase in investment expenditure of $\Delta \bar{I}$ results in an increase in the equilibrium level of income of $\Delta Y=\Delta I\left\{\frac{1}{1-c}\right\}$; what simultaneous increase in the quantity of money would be necessary in the present model in order that a horizontal shift in the investment demand schedule of $\Delta \bar{I}$ will result in an increase in the equilibrium level of $Y$ of $\Delta \bar{I}\left\{\frac{1}{1-c}\right\}$ ? In answering this, it is also shown that the resulting change in the equilibrium level of interest is zero (as is intuitively obvious).

A1.2. If there is no change in $\bar{M}$, a horizontal shift in the investment demand function of $\Delta \bar{I}$ will result in a rise in the equilibrium level of $Y$ of $\Delta \bar{I}\left\{\frac{1}{1-c+(a / b) l}\right\} \cdot \quad$ (The corresponding change in the equilibrium level of $r$ will be $\frac{l}{b}\left\{\frac{\Delta \vec{I}}{1-c+(a / b) l}\right\}$ (see (1.10) in the text). However, the desired change in $Y$ is $\Delta \bar{I}\left\{\frac{1}{1-c}\right\}$ and so the shortfall of equilibrium $Y$ is:-

$$
\Delta \bar{I}\left\{\frac{1}{1-c}-\frac{1}{1-c+\frac{a}{b} l}\right\}=\frac{\Delta \bar{I} \frac{a}{b} l}{(1-c)\left(1-c+\frac{a}{b} l\right)} .
$$

A1.3. A unit change in the stock of money has an impact on the equilibrium value of $Y$ of $\left\{\frac{a / b}{1-c+(a / b) l}\right\}$ (see (1.9) in the text). Therefore, the value of the desired increase in the money supply, $\Delta \bar{M}$, may be found by solving for $\Delta \bar{M}$ in:-

i.e.,

$$
\frac{\Delta \bar{I} \frac{a}{b} l}{(1-c)\left(1-c+\frac{a}{b} l\right)}=\frac{\Delta \bar{M} \frac{a}{b}}{1-c+\frac{a}{b} l}
$$

(A1.2)

$$
\Delta \bar{M}=\frac{l \Delta \bar{I}}{1-c} .
$$

That a simultaneous shift in the investment demand schedule of $\Delta \bar{I}$ and a rise in $\bar{M}$ of $\left\{\frac{l \Delta \bar{I}}{1-c}\right\}$ does change the value of $Y$ by $\left\{\frac{\Delta \bar{I}}{1-c}\right\}$ can be checked by putting these values in equation (1.9) and finding the increase in $Y$ relative to the original value. That $\Delta r=0$ may be seen by examining (1.10); the only 
changes which occur, as between the old and the new levels of $Y$ and $r$, are:-

$$
\begin{aligned}
& \frac{l}{b}\left\{\frac{\Delta \bar{I}}{1-c+\frac{a}{b} l}\right\}-\frac{\Delta \bar{M}}{b}\left\{\frac{1-c}{\left.1-c+\frac{a}{b} l\right\}}\right) \\
= & \frac{l}{b}\left\{\frac{\Delta \bar{I}}{1-c+\frac{a}{b} l}\right\}-\left\{\frac{(l \Delta \bar{I})}{b(1-c)}\right\}\left\{\frac{1-c}{1-c+\frac{a}{b} l}\right\} \\
= & 0 .
\end{aligned}
$$

APPENDIX 2: A LINEAR VERSION OF THE HUDSON MODEL

OF THE TRADE CYCLE

A2.1. In this appendix it is shown how the model of section 1 can be extended easily to make a linear version of Hudson's model of the trade cycle. The extensions are two:-investment is made a function of the level of real output and the capital stock as well as of the rate of interest; and the period to period changes in the capital stock are taken into account.

\section{Goods market equilibrium}

A2.2. The equilibrium condition in the goods market in the short run is still that ex ante $S=$ ex ante $I$. However, $I$ is now a function of the level of real output and the existing capital stock $(K)$ as well as of the rate of interest. For simplicity, $S$ remains a function of income only (Hudson makes $S$ a function of $r$ as well, but this does not alter the analysis in any essential way). At low levels of $Y$ (less than $\bar{Y}$ ), the marginal propensity to save, $(s=1-c)$, is assumed to be greater than the marginal propensity to invest $\left(a_{1}\right)$. At high levels, the opposite result is assumed, i.e., $s<a_{3}$. Thus

$$
S=-\bar{A}+(1-c) Y=-\bar{A}+s Y
$$

and, for $Y \leq \bar{Y}$,

$$
I=\bar{I}-a r+a_{1} Y-a_{2} K, \quad\left(a_{1}<s\right) .
$$

For $Y \geq \bar{Y}$,

$$
I=\bar{I}-a r+a_{1} \bar{Y}+a_{3}(Y-\bar{Y})-a_{2} K, \quad\left(a_{3}>s\right) .
$$

A2.3. In any short period (as defined by a given value of $K$ ) and for all values of $Y$, there are, therefore, unique values of $r$ which are consistent with the equilibrium in the goods market. The $I S$ schedule is obtained by imposing the goods market equilibrium condition to obtain 
(i) for $Y \leq \bar{Y}$,

$$
\text { (A2.3a) } \quad r=\frac{\bar{I}+\bar{A}-a_{2} K}{a}-\left(\frac{s-a_{1}}{a}\right) Y
$$

(ii) for $Y \geq \bar{Y}$,

$$
\text { (A2.3b) } \quad r=\frac{\bar{I}+\bar{A}-\left(a_{3}-a_{1}\right) \bar{Y}-a_{2} K}{a}+\left(\frac{a_{3}-s}{a}\right) Y .
$$

The IS schedule therefore contains two sections, one downward-sloping, the other, upward-sloping (see Fig. A2.1).

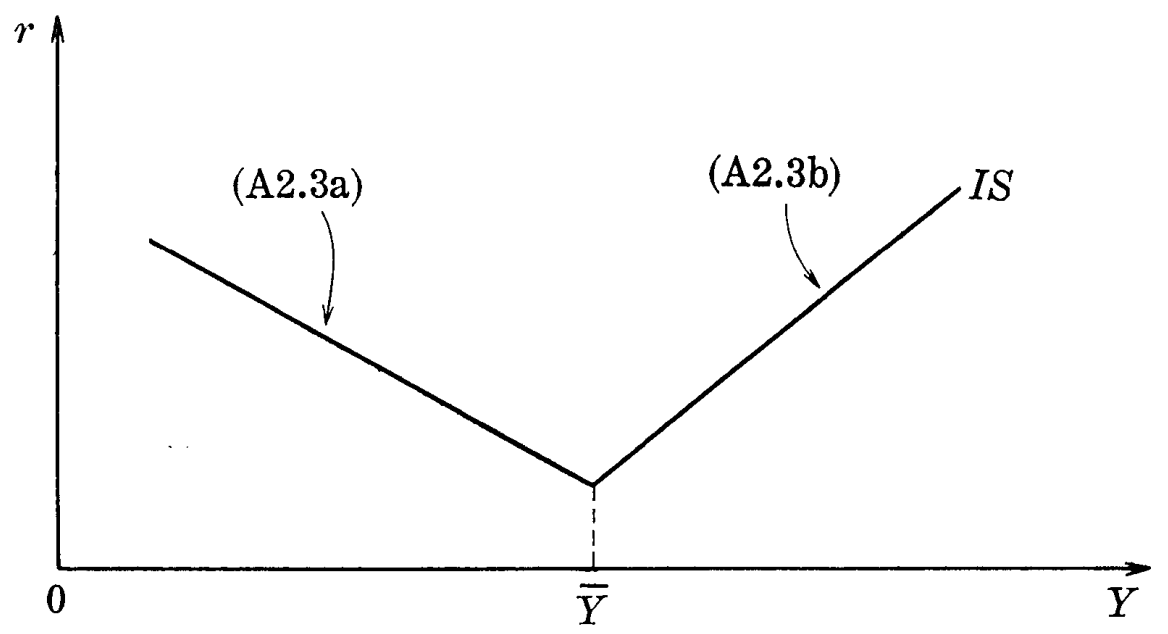

Fig. A2.1

\section{Money market equilibrium}

A2.4. A given money supply, $\bar{M}$, is assumed (but the analysis can be modified easily to include a flexible money supply, say $M=\bar{M}+b_{1}\left(Y-Y^{*}\right)$ where $Y^{*}=\frac{b r^{*}+\bar{M}-M^{*}}{l}$ and $b_{1}<l$, see below). The equilibrium condition implies that:-

$$
r=\frac{M^{*}-\bar{M}}{b}+\frac{l}{b} Y
$$

for $r \geq r^{*}$ and $Y \geq \frac{b r^{*}+\bar{M}-M^{*}}{l}\left(=Y^{*}\right)(>\bar{Y})$.

For $Y \leq Y^{*}$,

$$
\text { (A2.4a) } r=r^{*} .
$$

At $Y=\frac{\bar{M}}{l}$,

$$
\text { (A2.4b) } \quad r=\frac{M^{*}}{b}
$$

and $Y$ cannot exceed $\bar{M} / l$, no matter how high is the value of $r$. 
The $L M$ schedule therefore has three sections (see Fig. A2.2). ${ }^{(1)}$

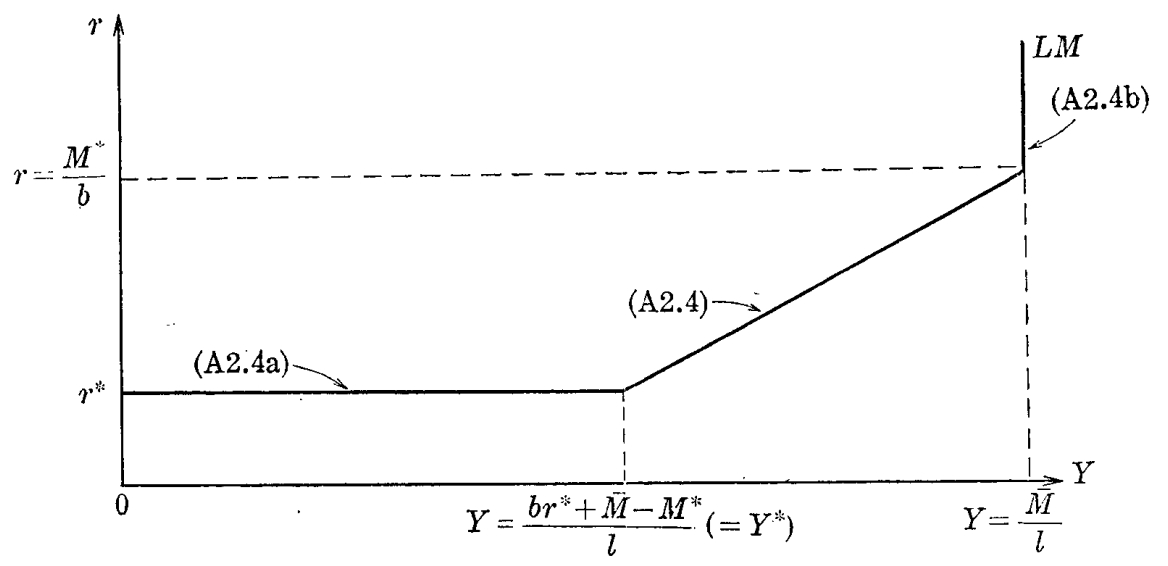

Fig. A2.2

Full equilibrium in the short period

A2.5. Next, the $L M$ and $I S$ schedules are put together. There are, in general, two possible stable equilibrium positions $(A$ and $C$ ) and one unstable one $(B)$ (see Fig. A2.3). At $A$, which is the intersection of (A2.3a) with (A2.4a),

(1) With flexible money supply for $Y \leq Y^{*}$,

$$
M=\bar{M} \quad \text { and } \quad r=r^{*}
$$

For $Y \geq Y^{*}$,

$$
\text { (A2.ii) } \quad M=\bar{M}+b_{1}\left(Y-Y^{*}\right) \quad \text { and } \quad r=\frac{M^{*}-\bar{M}+b_{1} Y^{*}}{b}+\left\{\frac{l-b_{1}}{b}\right\} Y
$$

The $L M$ schedule therefore has two sections only (see Fig. A2.i) and the upward-sloping section has a flatter slope than its counterpart for a constant money supply.

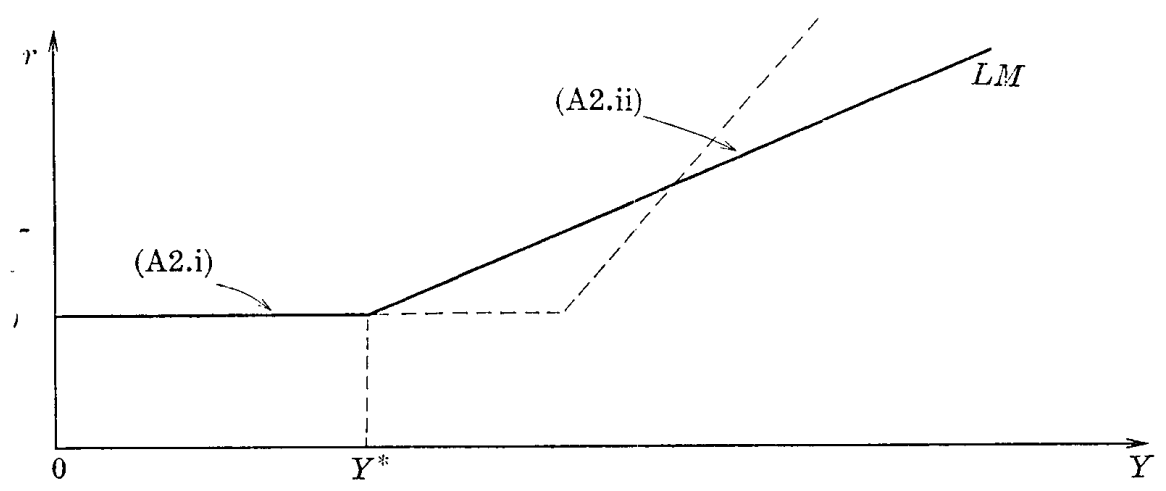

Fig. A2.i

The value of $Y^{*}$ depends on the value of $\bar{M}$. If the value of $\bar{M}$ with a flexible money supply differs from its value with a constant money supply, the $L M$ schedule starts to rise at a lower (higher) level of $Y$, according to whether the value for the flexible supply is less than (greater than) the value for the constant supply. (The former case is shown in Fig. A2.i) 
(A2.5a)

$$
Y=\frac{\bar{I}+\bar{A}-a_{2} K-a r^{*}}{s-a_{1}}
$$

[Notice that (A2.5a) is the simple goods market solution, i.e., (1.9a) of the text, if $a_{1}$ and $a_{2} K$ are ignored.]

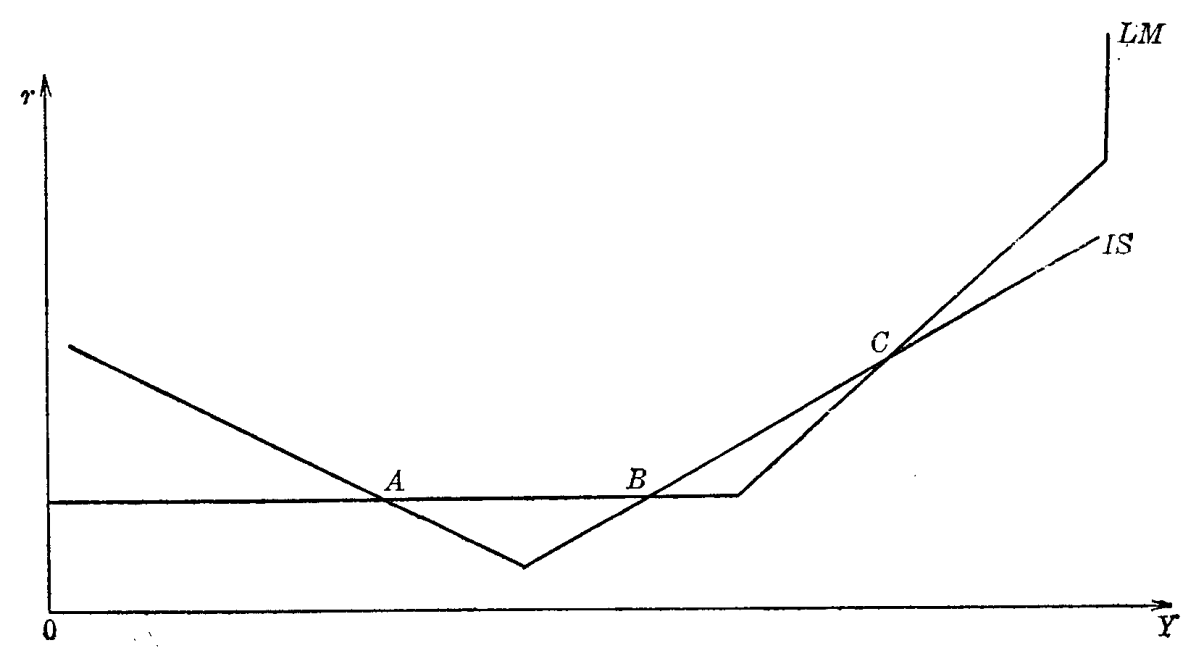

Fig. A2.3

A2.6. At $C$ (the (A2.3b), (A2.4) intersection),

(A2.5b)

$$
Y=\frac{\frac{\bar{I}+\bar{A}-\left(a_{3}-a_{1}\right) Y-a_{2} K}{a}-\frac{M^{*}-\bar{M}}{b}}{\frac{l}{b}-\frac{a_{3}-s}{a}}
$$

$I S$ is less steep than $L M$ at $C$, which implies that $\frac{l}{b}>\frac{a_{3}-s}{a}$ which implies in turn that the numerator of (A2.5b) is positive, for $Y$ must be positive.

[(A2.5b) may also be written as:-

$(\mathrm{A} 2.5 \mathrm{c})$

$$
Y=\frac{\bar{I}+\bar{A}-\left(a_{3}-a_{1}\right) \bar{Y}-a_{2} K-\frac{a}{b}\left(M^{*}-\bar{M}\right)}{1-c-a_{3}+\frac{a}{b} l}
$$

which becomes the goods and money market solution, i.e., (1.9) of the text if $a_{1}, a_{3}, \bar{Y}$ and $a_{2} K$ are ignored. $]^{(2)}$

(2) The corresponding condition with a flexible money supply is:

(A2.iii)

$$
Y=\frac{\frac{\bar{I}+\bar{A}-\left(a_{3}-a_{1}\right) \bar{Y}-a_{2} K}{a}-\frac{M^{*}-\bar{M}+b_{1} Y^{*}}{b}}{\frac{l-b_{1}}{b}-\frac{a_{3}-s}{a}}
$$


The cycle

A2.7. Suppose the story is started in a slump, i.e., at A. Assume that realised investment per period [as given by (A2.5a) and (A2.2a)] is less than depreciation. $K$ will fall from period to period and the $I S$ curve will rise (because $I$ is greater, cet par, the lower is the value of $K$ ) until $A$ and $B$ coincide. The economy will then expand to the boom position, $C$. At $C$, it may be supposed that gross capital formation is greater than depreciation; the IS curve therefore falls from period to period until $C$ and $B$ coincide, and the economy returns to $A$.

A2.8. Hudson adds a number of refinements to this basic analysis which will not be discussed here. The main purpose of this appendix has been to show how this dynamic theory of economic fluctuations can be linked on simply to the comparative statics analysis of the Keynesian system. 